\title{
Premature fetal tissues are possible source of valuable mesenchymal stem cells
}

\author{
Filip A. Dąbrowski ${ }^{1}$, Anna Burdzinska², Agnieszka Kulesza² ${ }^{2}$ Beata Kaleta ${ }^{3}$, \\ Leszek Pączek ${ }^{2,4}$, Mirosław Wielgoś ${ }^{1}$ \\ ${ }^{1} 1$ st Department of Obstetrics and Gynecology; Medical University of Warsaw, Warsaw, Poland \\ 2Department of Immunology, Transplant Medicine and Internal Diseases, The Medical University of Warsaw, Warsaw, Poland \\ ${ }^{3}$ Department of Clinical Immunology, Transplantation Institute, Medical University of Warsaw, Poland \\ ${ }^{4}$ Department of Bioinformatics, Institute of Biochemistry and Biophysics, Polish Academy of Sciences, Warsaw, Poland
}

\begin{abstract}
Objectives: Comparison of the ability to inhibit alloactivated lymphocytes proliferation of human Wharton Jelly (WJ) and amniotic membrane (AM) mesenchymal stem cells (MSCs) from preterm and term pregnancies.

Material and methods: Term-WJ-MSCs $(n=5)$ and Preterm-WJ-MSCs $(n=1)$ were obtained from tissue explants by adherent method. Term-AM-MSCs $(n=5)$ and Preterm-AM-MSCs $(n=1)$ were obtained by tripsin and collagenase digestion method. Term and Preterm MSCs phenotype was confirmed in vitro by flow cytometry. To evaluate the potential of fetal and adult MSCs to diminish immunological response mixed lymphocytes reaction (MLR) has been performed.

Results: Term and Preterm cells were positively identified as MSCs by the expression of CD73 and CD90 and CD105 with simultaneous absence of CD11b, CD14, CD19, CD34, CD45 and HLA-DR. The mean inhibition of allostimulated lymphocytes after addition of fetal derived MSCs amounted 64.8\% for term AM-MSCs and $42.1 \%$ for term WJ-MSCs (for both populations the effect was statistically significant, $\mathrm{p}<0.01$ ). The addition of preterm-MSCs to MLR resulted in reduction of stimulated lymphocytes proliferation by $64.9 \%$ for AM-MSCs and $86.1 \%$ for WJ-MSCs.

Conclusions: Presented results suggest that preterm fetal tissues contain MSCs which posses similar immunosuppressive capacity as those from term pregnancies. In the future MSCs from the umbilical cord and amnion can be potentially used to prevent immuno-dependent injuries in premature newborns.
\end{abstract}

Key words: mesenchymal stem cells, immunomodulation, amnion, umbilical cord, premature delivery

Ginekologia Polska 2017; 88, 4: 191-197

\section{INTRODUCTION}

The recent progress in clinical translation of basic stem cell research is based on two main types of human cells: Pluripotent stem cells (embryonic or induced) and mesenchymal stem cells (MSCs). With the advance of science we currently know MSCs have different characteristic depending on the tissue they originate, donor age and culture conditions [1-3]. Therefore, the key challenge for researchers remain fitting best type of stem cells for specific therapies. MSCs derived from fetal tissues such as Wharton Jelly (WJ-MSCs) and amniotic membrane (AM-MSCs) are very promising for vide spectrum of applications. Numerous data indicate that these early-stage cells exert significantly lower immunogenicity but similar immunomodulatory and neuroprotective potential when compared to cells derived from mature tissues $[2,4]$. It was demonstrated, that MSCs isolated from perinatal tissues not only fulfill general characteristics of MSCs $[2,5,6]$, but present higher proliferative potential and less typical signs of senescence at an early stage in comparison to adult, bone marrow or adipose derived MSCs $[2,7]$. Although the mechanism of MSCs therapeutic action is not fully elucidated, there is mounting evidence that paracrine enhancement of endogenous regenerative potential and selective modulation of immune system is 
predominantly responsible for the vast MSCs effects after transplantation, not as previously thought simple replacement of damaged tissue $[8,9]$.

This feature can and should be introduced in prevention and treatment of perinatal brain hemorrhage and acute respiratory syndrome associated with preterm deliveries. The use of autologous MSCs from fetal tissues gives opportunity to prompt start of the therapy, without the burden of matching recipient and the donor. Our previous research has proven that fetal derived MSCs from WJ and AM have different, but promising cytokine profile and both share the capacity to inhibit proliferation of allo-activated lymphocytes in an in vitro transplantation model [2]. It is known that fetal MSCs obtained from fetal tissues from term pregnancies complicated with preeclampsia have similar features when compared with healthy pregnancies [10]. In current research we try to find out if immature tissues obtained from preterm delivery are rich in MSCs with similar immunomodulative properties as ones from term deliveries.

\section{MATERIAL AND METHODS}

\section{Amniotic membrane and umbilical cord donation}

Ethical approval was received from the Medical University of Warsaw Ethics Committee and informed consent was obtained from all women who donated tissues for the experiment. Amniotic membrane ( $\left.\mathrm{AM}, 10 \mathrm{~cm}^{2}\right)$ and umbilical cord (WJ, $10 \mathrm{~cm}$ ) samples were taken from 5 healthy pregnant patients undergoing scheduled cesarean section at term of delivery, and one patient who had premature delivery at 29 weeks due to spontaneous contractions. Similar to our previous experiments AM and WJ fragments were placed in sterile containers with $\mathrm{PBS}+1 \%$ penicillin and streptomycin solution, and transferred to the laboratory unit within 1 to 2 hours. All further stages of isolation and cell culture were performed under a laminar flow hood.

\section{Amniotic membrane}

Amnion layer was mechanically separated from the chorion and, after rinsing of blood and debris it was immersed in $70 \%$ ethanol solution for 3 seconds to eliminate potential fungal or bacterial contamination. Tissue was washed twice in standard Phosphate Buffered Saline (PBS) and incubated in $0.25 \%$ trypsin-EDTA solution (Gibco) for $1 \mathrm{~h}$ in $37^{\circ} \mathrm{C}$ with continuous stirring on roller mixer, washed again in PBS and exposed to $1 \mathrm{mg} / \mathrm{mL}$ collagenase type I (Sigma-Aldrich), C0130)/0.025mg/mL DNAse (Sigma-Aldrich) solution. The membrane was incubated in $37^{\circ} \mathrm{C}$ for 60 to 90 minutes until complete tissue disintegration. The released cells were centrifuged, washed twice, suspended in growth medium (GM) consisting of DMEM-LG (Dulbecco's modified Eagle's Medium with low glucose; Lonza) supplemented with fetal calf serum (FCS; 15\%; Lonza) and antibiotic-antimycotic solu- tion (Penicillin-streptomycin-amfoterycin; 1.5\%; Invitrogen), and seeded on $\varnothing 100 \mathrm{~mm}$ culture dish (BD Primaria ${ }^{\mathrm{TM}}$ ). After 48 hours the dishes were washed with PBS to remove non-adherent cells and debris and suspended in GM again. When primary cultures reached subconfluency, cells were detached by short trypsinisation ( 2 min in $0.25 \%$ trypsin with $1 \mathrm{mM}$ EDTA; Invitrogen) and replated at a density of $5.0 \times 10^{3}$ cells $/ \mathrm{cm}^{2}$ for further growth.

\section{Wharton Jelly}

Collected umbilical cord fragments were washed from blood, devascularised and cut with sterile surgical knife into about $3 \mathrm{~mm}^{3}$ fragments and placed on $\varnothing 100 \mathrm{~mm}$ culture dish (BD Primaria ${ }^{\mathrm{TM}}$ ) in $\mathrm{GM}$ and cultured in $37^{\circ} \mathrm{C}$ and $5 \%$ $\mathrm{CO}_{2}$ atmosphere. The medium was changed every $2-3$ days without touching the explants. After 10 days, the explants were collected, the dishes washed to remove non-adherent cells and debris. The MSCs cells which migrated from the WJ explants were detached from the culture dish and reseeded on a new dish in a density of $5.0 \times 10^{3}$ cells $/ \mathrm{cm}^{2}$ for further growth.

All experiments were performed on cells (all types) between passage 3 and 5 .

\section{Flow cytometry, differentiation assay, and morphology of acquired cells}

The criteria of human MSCs identification established in 2006 by the International Society for Cell Therapy were tested. Both, WJ and AM-derived cells displayed typical MSCs spindle shape morphology and created colonies on plastic surface regardless of fetal tissues maturity. To evaluated the multipotency of isolated MSCs, cells were induced to differentiate into adipocytes, osteocytes and chondrocytes using adequate differentiation media according to manufacturer protocols (Human Mesenchymal Stem Cell Functional Identification Kit; R\&D Biosystems, Minneapolis, USA). MSCs osteogenic potential was then confirmed by staining mineral deposits with Alizarin Red solution (Sigma-Aldrich). Lipid droplets accumulated by adipocytes were visualized with Oil Red O solution (Sigma-Aldrich). To prove the induction of chondrogenesis in MSCs, toluidine blue staining was performed, in which cartilaginous extracellular matrix was stained purple (metachromasia). The results of differentiation is shown on Figure 1. The immunophenotype of MSCs was assessed by flow cytometry, using Human MSCs Analysis Kit (BD Stemflow) for the presence of cell surface antigens CD73, CD90, CD105, and the absence of CD34, CD45, CD11b, CD19 and HLA-DR.

\section{Mixed lymphocytes reaction (MLR)}

One of approved methods to confirm MSCs immunosuppressive potential is to assess their capacity to inhibit 

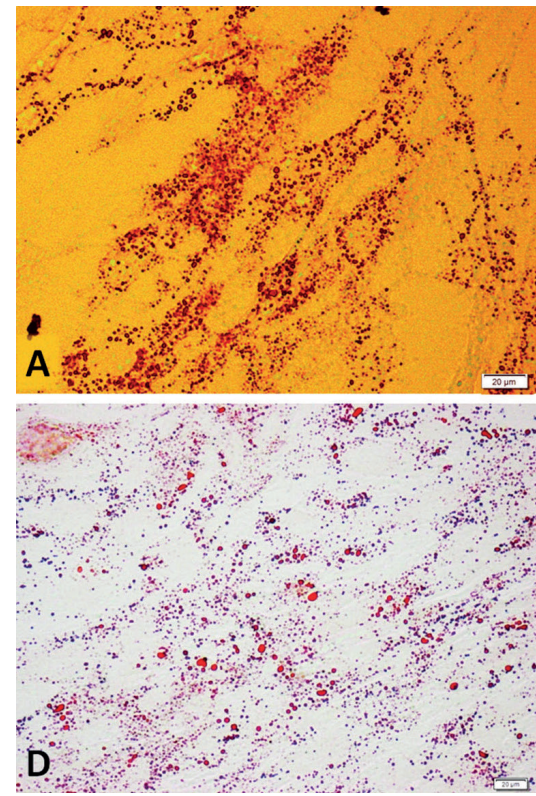

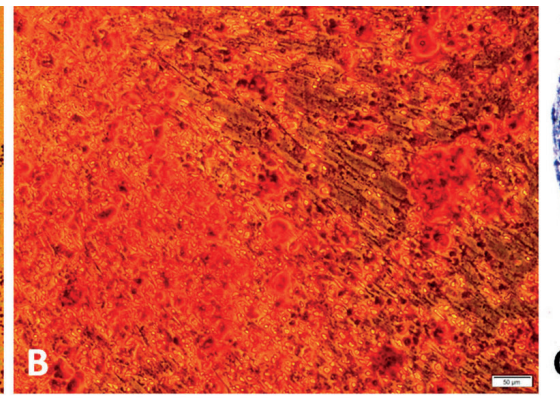

C
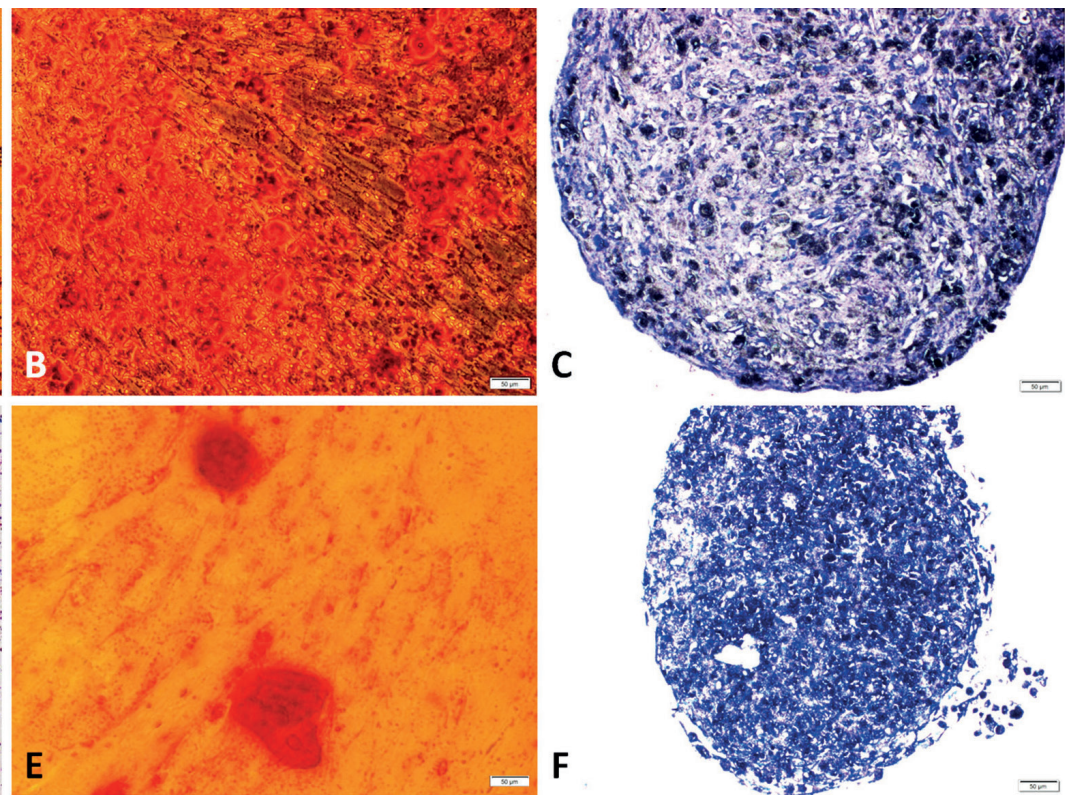

Figure 1. Bright field images. Both amnion-derived (upper row) and umbilical cord-derived (lower row) can be differentiated into adipocytes $(A, D$ - intracellular fat deposits stained in red), osteoblasts ( $B, E$ - calcium deposits in cellular walls stained in red), and chondroblasts (C, F - cartilaginous extracellular matrix stained purple). Scale bars: $20 \mu \mathrm{m}(\mathrm{A}, \mathrm{D}), 50 \mu \mathrm{m}(\mathrm{B}, \mathrm{C}, \mathrm{E}, \mathrm{F})$

proliferation of allo-activated lymphocytes in Mixed Lymphocyte Reaction (MLR) [11]. At first peripheral blood mononuclear cells (PBMCs) were isolated from venous blood of healthy blood donors by density gradient centrifugation onto Histopaque-1077 (Sigma Aldrich). Half of the isolated PBMCs from each donor were inactivated by gamma irradiation for $90 \mathrm{~min}$.

MLR aims to measure the proliferation rate of lymphocytes from donor $A$ in the response to lymphocytes from unrelated donor B. To assess activity of lymphocyte from a certain donor, one population was always irradiated (marked as " $x$ "). Therefore, cells were tested in the following combinations: $\mathrm{ABx}$ and $\mathrm{BAx}$. The basic proliferation level was measured by control combinations: $A A x$ and $B B x$ To evaluate the in vitro immunosuppressive potential of MSCs, they were added to the mixture of lymphocytes from donors $A$ and B (PBMCs donors were unrelated to MSCs donor). The experiments were performed on a 96-well flat-bottom plates (Greiner). Lymphocytes were seeded in concentration of $1 \times 10^{5}$ cells/well per donor and were cultured with or without addition of MSCs $\left(1 \times 10^{4} /\right.$ well). PBMCs cultures without MSCs were used as controls. Cells were cultured for 5 days at $37^{\circ} \mathrm{C}$ in a humidified atmosphere with $5 \%$ $\mathrm{CO}_{2}$. After 5 days, the cells were pulsed with $1 \mu \mathrm{Ci} /$ well of $3 \mathrm{H}$-thymidine $(113 \mathrm{Ci} / \mathrm{nmol}, \mathrm{NEN})$ for the last 18 hours of the incubation and harvested with an automated cell harvester (Skatron). The amount of 3H-thymidine incorporated into the cells was measured using a Wallac Microbeta scintillation counter (Wallac), giving the level of radioactivity as
'Corrected Counts per Minute' (CCPM). Experiments were performed in triplicates.

\section{Statistical method}

Statistical analysis was performed in order to evaluate the significance of term MSCs effect on lymphocyte proliferation in MLR. The data distribution was assessed using Shapiro-Wilk test. Due to abnormal distribution and limited size of analyzed groups $(n=10)$, non-parametric Wilcoxon matched-pairs signed-ranks test was used. A level of significance was set at $\mathrm{p}<0.05$.

\section{RESULTS}

\section{Expression of surface markers}

\section{in MSCs using flow cytometry analysis}

The cluster of differentiation antigens (CD) profiles of cultured cells were rated by flow cytometry after 3-4 passages. It was found that mean expression of CD73, CD90, CD105 surface markers with simultaneous absence of: CD11b, CD14, CD19, CD34, CD45 and HLA-DR was for term AM-MSCs 72.1\% (median $87.6 \%, \mathrm{SD}=0.22$ ). In this population, a mean of $90.6 \%$ (median $91.6 \%, \mathrm{SD}=0.13$ ) has been positive for CD44, an additional MSCs marker. In preterm AM-MSCs samples, the mean values were even better $-96.2 \%$ and $94.1 \%$ respectively. The results for WJ-MSCs was similar and can be seen in Table 1. Despite the same procedures and conditions, the tempo of culture varied between samples due to ontogenic dfifferences, but in the case of premature AM we were able to harvest 8 million of MSCs after 7 days from the delivery. 
Table 1. MSC's antigen profiles in flow cytometry

\begin{tabular}{|l|c|c|c|c|c|c|}
\hline & $\begin{array}{c}\text { Preterm WJ- } \\
\text { MSCs }\end{array}$ & $\begin{array}{c}\text { Preterm AM- } \\
\text { MSCs }\end{array}$ & $\begin{array}{c}\text { Term WJ-MSCs } \\
\text { [mean value] }\end{array}$ & $\begin{array}{c}\text { Term AM-MSCs } \\
\text { [mean value] }\end{array}$ & $\begin{array}{c}\text { Term WJ-MSCs } \\
\text { [median value] }\end{array}$ & $\begin{array}{c}\text { Term AM-MSCs } \\
\text { [median value] }\end{array}$ \\
\hline $\begin{array}{l}\text { 1. CD73, CD90, } \\
\text { CD105 (+) }\end{array}$ & $92.60 \%$ & $96.20 \%$ & $79.60 \%$ & $72.20 \%$ & $92.80 \%$ & $87.60 \%$ \\
\hline $\begin{array}{l}\text { 2. CD11b, CD14, } \\
\text { CD19, CD34, CD45, }\end{array}$ & $96.70 \%$ & $94.10 \%$ & $86.78 \%$ & $90.60 \%$ & $88.05 \%$ & $91.60 \%$ \\
\hline HLA-DR (-) & & & 0.197456 & 0.239502 & 0.154108 & 0.218873 \\
\hline SD1 & & 0.11004 & 0.103928 & 0.207586 & 0.126619 \\
\hline SD2 & & & & & & \\
\hline
\end{tabular}

MSCs from premature tissues share immunosuppressive properties of term fetal MSCs Premature MSCs inhibit proliferation of lymphocytes stimulated by PBMCs from the unrelated donor in similar way as cells derived at term

Mixing allogenic, irradiated PBMCs from two donors results in a massive increase in lymphocytes proliferation $(p<0.01$ in comparison to auto-stimulated cells). The addition of MSCs to MLR, regardless of the source, inhibited stimulation of lymphocytes. For term WJ-MSCs the mean proliferation of PBMCs [CCPMx103] dropped from $786( \pm 127.6)$ to 388 ( \pm 84.3 ), for term AM-MSCs form $1242( \pm 331$ ) to 329 $( \pm 76.75)$, for preterm WJ-MSCs from $584( \pm 130)$ to $86( \pm 3.2)$, and preterm AM-MSCs from 1059 ( \pm 244 ) to $358( \pm 46)$. Data are presented on Figures 2 and 3 . For each term MSCs type, the inhibition of PBMCs proliferation was statistically significant at the level of 1\%; for term AM-MSCs $p=0,005$ (Wilcoxon test), for term WJ-MSCs $p=0,004$ (Wilcoxon test). The level of MLR inhibition induced by preterm MSCs did not differ from term MSCs, regardless of tissue type.

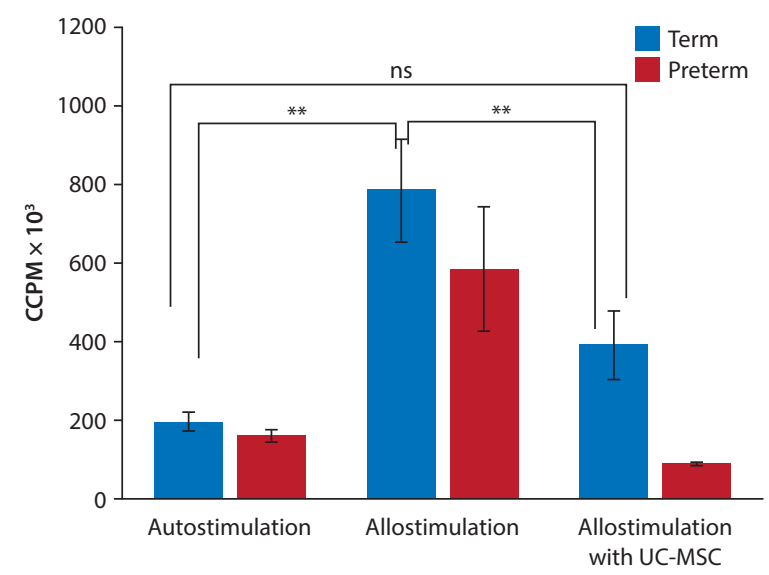

Figure 2. The effect of adding term and preterm AM-MSC's to MLR, Addition of term MSC's leads to significant decline in lymphocytes proliferation with $p=0.005$ (Wilcoxon test). The effect of preterm cells is equally good

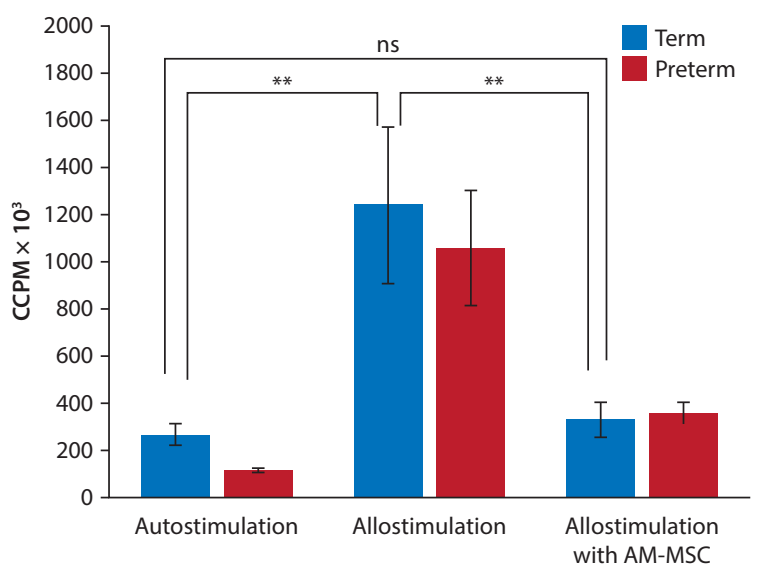

Figure 3. The effect of adding term and preterm WJ-MSC's to MLR, Addition of term MSC's leads to significant decline in lymphocytes proliferation with $p=0.004$ (Wilcoxon test). The effect of preterm cells is equally good

\section{The extend of MLR inhibition does not differ between analyzed MSCs types}

The mean inhibition of proliferation rate after addition of premature MSCs to the MLR is similar to MSCs derived at term. To avoid distortion of the results due to individual differences in donor's lymphocytes activity we calculated'MLR ratio' by dividing the result of allo-stimulation by allo-stimulation with MSCs. Mean MLR ratio for Term-AM-MSCs was 3.12 and for Preterm AM-MSCs 2.90 (median). For WJ-MSCS for term samples mean MLR ratio was 2.43 and for preterm median ratio was 7.82. In statistical evaluation (the Wilcoxon test ), the average decline did not differ significantly between AM-MSCs and WJ-MSCs.

\section{DISCUSSION}

Since 1961 when James Till, a biophysicist, and Ernest McCulloch, a haematologist, described their accidental findings which demonstrated the existence of rare cells that can proliferate and rebuild hematopoietic lineages, stem cells research was seeping towards the very centre of scientific 
world [12]. Later, they defined stem cells as those, with the capacity to both self-renew and differentiate to various adult cells [13]. Researchers had to overcome tremendous obstacles to push knowledge to the point where we stand today. The history of stem cell research is a line of battles waged not only at the laboratory bench, but also on the field of ethics. In 2016 the international guidelines for development of research and the clinical application of stem cell science has been finally accepted [14]. The recent advance in clinical translation of basic stem cell research is mainly based on following types of human cells: embryonic stem cells (ESCs) or induced pluripotent stem cells (iPSCs) and mesenchymal stem cells. Main legal and ethical questions concerning the use stem cells are issues affecting creation of human embryos for research purpose only (ESCs), potential oncogenesis (ESCs and iPSCs) and invasive procedures such as bone marrow aspiration or liposuction needed to obtain these cells (MSCs) [15-19].

Even though mitochondrial-replacement techniques (MRT) already has been used to replace dysfunctional mitochondria in human egg with ones obtained from healthy donors in United Kingdom, many ethics warn it may lead to return of eugenic experiments. Similar questions arise concerning possible injuries and comorbidities of bone marrow and adipose tissue donors. Recently, researchers focus on perinatal tissues like Wharton Jelly and amniotic membrane. Those tissues were proven to contain vast amount of mesenchymal stem cells $[2,20]$ and comparing with other sources does not evoke ethical issues because typically fetal tissues are disposed as medical waste and MSCs derivation does not require any additional procedures for the patients. Increasing donor age is another factor that negatively affects the immunoregulatory properties of both adipose and bone marrow derived mesenchymal stem cells [21].

The frequency of MSCs in adipose tissue and bone marrow is about $3 \%$ and $0.001 \%$ of nucleated cells, respectively. It is not sufficient enough to dream about treating rapidly deteriorating patients [22-24]. Our data confirms previous findings that fetal tissues can be rich source of autologous MSCs, providing enough material for treatment even within hours from the delivery (with typical doses of $1 \mathrm{mln} / \mathrm{kg}$ ) and sustainable source for continuing of the therapy.

Fetal MSCs posses higher proliferative potential and less typical signs of senescence at an early stage in comparison to adult ASCs [7]. MSCs derived from Wharton Jelly are known for their ability to modulate immune response and have been successfully used in therapy of acute liver failure [25] and ischemic stroke [9] and lung injury characterized by alveolar damage [26]. In four year observation of patients with refractory systemic lupus erythematosus, no transplantation-related adverse events and the induction of clinical remission and improvement in organ function in drug-resistant SLE patients have been reported [27].
Recent publications demonstrate that WJ-MSCs has a higher proliferation rate, a greater expansion capability, enhanced neurotrophic factors gene expression and spontaneous tendency toward a neural lineage differentiation when compared with MSCs from bone marrow [3].

More and more research concentrate on the effect of different culture conditions on the qualities of obtained cells. Lowering oxygen level $<5 \%$ was shown to have a beneficial impact on WJ-MSCs. It improved their rate of proliferation, and maintenance of stemness properties during the culture [1]. Such factors like maternal age, the distance of collected umbilical cord fragment from the placenta were also investigated. It was found that WJ-MSCs derived from the extreme cord segments are better source of MSCs compared with cells from the middle segment because of their higher proliferation rate and viability [28]. In the research on 100 term pregnancies, from five maternal age groups (20-45 years), reduced number of cells as well as the level of MSCs markers expression were reported in older mothers [29].

MSCs show promise for cellular therapy for various diseases associated with inflammation or auto-immunological disorders. Despite fact that fetal MSCs have been shown to be non-tumorogenic [30], safety rules must be obeyed. MSCs were shown to interact with cancer cells, revoking them from a dormant state in breast cancer [31]. Other scientists consider their activity as antitumor, because despite co-culture with MSCs enhanced survival of nutrient deprived breast cancer cells in vitro, at the same time it suppressed their tumorigenicity which leads for the prevention of cancer recurrence [32]. Recent preclinical studies conducted on animal models prove a presumption that MSCs can be a tool in treating hypoxic-ischemic injury in neonates [33]. It was shown that transplantation of MSCs ameliorate inflammation-induced neuronal cellular degeneration, reduce microgliosis and prevent reactive astrogliosis in rat neonates [34]. Additionally, preclinical research demonstrate that MSCs-based therapies have potential for protecting the developing lung from injury. In expert's opinion the evidence supporting this potential therapeutic role has provided the basis for the initiation of phase I and II clinical trials in preterm neonates [35]. Based on these arguments, further clinical research is needed to ensure patient safety before MSCs application in treatment of premature neonates [36]. The cited research has been performed in animal model and according to authors best knowledge our results are the first confirming the efficacy of human premature MSCs.

\section{CONCLUSION}

Human Wharton Jelly and amniotic membrane derived mesenchymal stem cells can be easily obtained and cultured from premature tissues. Presented results suggest that preterm fetal tissues contain MSCs which show similar 
immunosuppressive capacity as ones from term pregnancies. Premature fetal MSCs from early third-trimester pregnancy have the capacity to inhibit proliferation of allo-activated lymphocytes in an in vitro transplantation model. In the future they may be potentially used to prevent immuno-dependent injuries in premature newborns.

\section{Acknowledgments}

Medical University ofWarsaw Grant, 1W51/PM11D/14/14 subdivision entitled:"Mesenchymal stem cells from fetal tissues as new source of material for regenerative medicine" - provided financial support for the conduct of the research.

This study was supported by the National Centre for Research and Development (Grant No. STRATEGMED1/233224/10/NCBR/2014; Project START).

\section{Authors contribution and conflict of interests}

Filip Dabrowski: performed study, analyzed data, wrote manuscript, no conflict of interests.

Anna Burdzinska: performed study, analyzed data, wrote manuscript, no conflict of interests.

Agnieszka Kulesza: performed study, analyzed data, no conflict of interests.

Beata Kaleta: performed study, analyzed data, no conflict of interests.

Leszek Paczek: analyzed data, wrote manuscript, no conflict of interests.

Miroslaw Wielgos: analyzed data, wrote manuscript, no conflict of interests.

\section{REFERENCES}

1. Lech W, Figiel-Dabrowska A, Sarnowska A, et al. Phenotypic, Functional, and Safety Control at Preimplantation Phase of MSC-Based Therapy. Stem Cells Int. 2016; 2016:2514917, doi: 10.1155/2016/2514917, indexed in Pubmed: 27651796.

2. Dabrowski FA, Burdzinska A, Kulesza A, et al. Mesenchymal Stem Cells from Human Amniotic Membrane and Umbilical Cord Can Diminish Immunological Response in an in vitro Allograft Model. Gynecol Obstet Invest. 2016 [Epub ahead of print], doi: 10.1159/000449199, indexed in Pubmed: 27627653.

3. Drela K, Lech W, Figiel-Dabrowska A, et al. Enhanced neuro-therapeutic potential of Wharton's Jelly-derived mesenchymal stem cells in comparison with bone marrow mesenchymal stem cells culture. Cytotherapy. 2016; 18(4): 497-509, doi: 10.1016/j.jcyt.2016.01.006, indexed in Pubmed: 26971678 .

4. Li X, Bai J, Ji X, et al. Comprehensive characterization of four different populations of human mesenchymal stem cells as regards their immune properties, proliferation and differentiation. Int J Mol Med. 2014; 34(3): 695-704, doi: 10.3892/ijmm.2014.1821, indexed in Pubmed: 24970492.

5. Pirjali T, Azarpira N, Ayatollahi M, et al. Isolation and Characterization of Human Mesenchymal Stem Cells Derived from Human Umbilical Cord Wharton's Jelly and Amniotic Membrane. Int J Organ Transplant Med. 2013; 4(3): 111-116, indexed in Pubmed: 25013662.

6. Dominici M, Le Blanc K, Mueller I, et al. Minimal criteria for defining multipotent mesenchymal stromal cells. The International Society for Cellular Therapy position statement. Cytotherapy. 2006; 8(4): 315-317, doi: 10.1080/14653240600855905, indexed in Pubmed: 16923606.

7. Christodoulou I, Kolisis FN, Papaevangeliou D, et al. Comparative Evaluation of Human Mesenchymal Stem Cells of Fetal (Wharton's Jelly) and Adult (Adipose Tissue) Origin during Prolonged In Vitro Expansion:
Considerations for Cytotherapy. Stem Cells Int. 2013; 2013: 246134, doi: 10.1155/2013/246134, indexed in Pubmed: 23533440.

8. Madrigal M, Rao KS, Riordan NH. A review of therapeutic effects of mesenchymal stem cell secretions and induction of secretory modification by different culture methods. J Transl Med. 2014; 12: 260, doi: 10.1186/s12967-014-0260-8, indexed in Pubmed: 25304688.

9. Obtulowicz P, Lech W, Strojek L, et al. Induction of Endothelial Phenotype From Wharton's Jelly-Derived MSCs and Comparison of Their Vasoprotective and Neuroprotective Potential With Primary WJ-MSCs in CA1 Hippocampal Region Ex Vivo. Cell Transplant. 2016; 25(4): 715-727, doi: 10.3727/096368915X690369, indexed in Pubmed: 26722842.

10. Pianta S, Magatti M, Vertua E, et al. Amniotic mesenchymal cells from pre-eclamptic placentae maintain immunomodulatory features as healthy controls. J Cell Mol Med. 2016; 20(1): 157-169, doi: 10.1111/jcmm.12715, indexed in Pubmed: 26515425.

11. Ock SA, Baregundi Subbarao R, Lee YM, et al. Comparison of Immunomodulation Properties of Porcine Mesenchymal Stromal/Stem Cells Derived from the Bone Marrow, Adipose Tissue, and Dermal Skin Tissue. Stem Cells Int. 2016; 2016: 9581350, doi: 10.1155/2016/9581350, indexed in Pubmed: 26798368.

12. Till JE, McCulloch EA, Till JE, et al. A direct measurement of the radiation sensitivity of normal mouse bone marrow cells. Radiat Res. 1961; 14(2): 213-222, indexed in Pubmed: 13776896.

13. Till JE, McCulloch EA. Hemopoietic stem cell differentiation. Biochim Biophys Acta. 1980; 605(4): 431-459, indexed in Pubmed: 7006701

14. Daley GQ, Hyun I, Apperley JF, et al. Setting Global Standards for Stem Cell Research and Clinical Translation: The 2016 ISSCR Guidelines. Stem Cell Reports. 2016; 6(6): 787-797, doi: 10.1016/j.stemcr.2016.05.001, indexed in Pubmed: 27185282.

15. Acosta ND, Golub SH. The New Federalism: State Policies Regarding Embryonic Stem Cell Research. J Law Med Ethics. 2016; 44(3): 419-436, doi: 10.1177/1073110516667939, indexed in Pubmed: 27587447.

16. Santavy $P$, Troubil M, Lonsky V. Pericardial tamponade: a rare complication of sternal bone marrow biopsy. Hematol Rep. 2013; 5(3): e13, doi: 10.4081/hr.2013.e13, indexed in Pubmed: 24179668.

17. Berber I, Erkurt MA, Kuku I, et al. An unexpected complication of bone marrow aspiration and trephine biopsy: arteriovenous fistula. Med Princ Pract. 2014; 23(4): 380-383, doi: 10.1159/000358173, indexed in Pubmed: 24481007.

18. You JeS, Chung YE, Baek SE, et al. Imaging Findings of Liposuction with an Emphasis on Postsurgical Complications. Korean J Radiol. 2015; 16(6): 1197-1206, doi: 10.3348/kjr.2015.16.6.1197, indexed in Pubmed: 26576108.

19. García-Fernández M, Méndez-Ferrer S. Under Pressure: When a Transformed Environment Pushes Cells to Malignancy. Cell Stem Cell. 2016; 19(5): 559-560, doi: 10.1016/j.stem.2016.10.012, indexed in Pubmed: 27814473.

20. Wang HS, Hung SC, Peng ST, et al. Mesenchymal stem cells in the Wharton's jelly of the human umbilical cord. Stem Cells. 2004; 22(7): 1330-1337, doi: 10.1634/stemcells.2004-0013, indexed in Pubmed: 15579650.

21. Wu LW, Wang YL, Christensen JM, et al. Donor age negatively affects the immunoregulatory properties of both adipose and bone marrow derived mesenchymal stem cells. Transpl Immunol. 2014; 30(4): 122-127, doi: 10.1016/j.trim.2014.03.001, indexed in Pubmed: 24632513.

22. Fraser JK, Wulur I, Alfonso Z, et al. Fat tissue: an underappreciated source of stem cells for biotechnology. Trends Biotechnol. 2006; 24(4): 150-154, doi: 10.1016/j.tibtech.2006.01.010, indexed in Pubmed: 16488036.

23. Abdallah BM, Kassem M. The use of mesenchymal (skeletal) stem cells for treatment of degenerative diseases: current status and future perspectives. J Cell Physiol. 2009; 218(1): 9-12, doi: 10.1002/jcp.21572, indexed in Pubmed: 18726996.

24. Lee JW, Fang X, Krasnodembskaya A, et al. Concise review: Mesenchymal stem cells for acute lung injury: role of paracrine soluble factors. Stem Cells. 2011; 29(6): 913-919, doi: 10.1002/stem.643, indexed in Pubmed: 21506195.

25. Shi $M$, Zhang $Z, X u R$, et al. Human mesenchymal stem cell transfusion is safe and improves liver function in acute-on-chronic liver failure patients. Stem Cells Transl Med. 2012; 1(10): 725-731, doi: 10.5966/sctm.2012-0034, indexed in Pubmed: 23197664.

26. Pierro M, lonescu L, Montemurro T, et al. Short-term, long-term and paracrine effect of human umbilical cord-derived stem cells in lung injury prevention and repair in experimental bronchopulmonary dysplasia. Thorax. 2013; 68(5): 475-484, doi: 10.1136/thoraxjnl-2012-202323, indexed in Pubmed: 23212278. 
27. Wang $\mathrm{D}$, Zhang $\mathrm{H}$, Liang J, et al. Allogeneic mesenchymal stem cell transplantation in severe and refractory systemic lupus erythematosus: 4 years of experience. Cell Transplant. 2013; 22(12): 2267-2277, doi: 10.3727/096368911X582769, indexed in Pubmed: 24388428

28. Lim J, Razi ZR, Law J, et al. MSCs can be differentially isolated from maternal, middle and fetal segments of the human umbilical cord. Cytotherapy. 2016; 18(12): 1493-1502, doi: 10.1016/j.jcyt.2016.08.003, indexed in Pubmed: 27727016.

29. Alrefaei Gl, Ayuob NN, Ali SS, et al. Effects of maternal age on the expression of mesenchymal stem cell markers in the components of human umbilical cord. Folia Histochem Cytobiol. 2015; 53(3): 259-271, doi: 10.5603/FHC.a2015.0022, indexed in Pubmed: 26339985.

30. Rebelatto CK, Aguiar AM, Moretão MP, et al. Dissimilar differentiation of mesenchymal stem cells from bone marrow, umbilical cord blood, and adipose tissue. Exp Biol Med (Maywood). 2008; 233(7): 901-913, doi: 10.3181/0712-RM-356, indexed in Pubmed: 18445775.

31. Quail DF, Joyce JA. Microenvironmental regulation of tumor progression and metastasis. Nat Med. 2013; 19(11): 1423-1437, doi: 10.1038/nm.3394, indexed in Pubmed: 24202395.
32. Bartosh TJ, Ullah M, Zeitouni S, et al. Cancer cells enter dormancy after cannibalizing mesenchymal stem/stromal cells (MSCs). Proc Natl Acad Sci U S A. 2016; 113(42): E6447-E6456, doi: 10.1073/pnas.1612290113, indexed in Pubmed: 27698134.

33. Ophelders DR, Wolfs TG, Jellema RK, et al. Mesenchymal Stromal Cell-Derived Extracellular Vesicles Protect the Fetal Brain After Hypoxia-Ischemia. Stem Cells Transl Med. 2016; 5(6): 754-763, doi: 10.5966/sctm.20150197, indexed in Pubmed: 27160705.

34. Drommelschmidt K, Serdar M, Bendix I, et al. Mesenchymal stem cell-derived extracellular vesicles ameliorate inflammation-induced preterm brain injury. Brain Behav Immun. 2017; 60: 220-232, doi: 10.1016/j. bbi.2016.11.011, indexed in Pubmed: 27847282.

35. Strueby L, Thébaud B. Mesenchymal Stromal Cell-Based Therapies for Chronic Lung Disease of Prematurity. Am J Perinatol. 2016;33(11): 1043 1049, doi: 10.1055/s-0036-1586115, indexed in Pubmed: 27603532.

36. Bibber B, Sinha G, Lobba ARM, et al. A review of stem cell translation and potential confounds by cancer stem cells. Stem Cells Int. 2013; 2013: 241048, doi: 10.1155/2013/241048, indexed in Pubmed: 24385986. 